\title{
The Relationship between Cognitive Ability, Emotional Intelligence and Creativity
}

\author{
Adrian Furnham 1,2 \\ ${ }^{1}$ Department of Clinical, Educational, and Health Psychology, University College London, London, UK \\ ${ }^{2}$ Norwegian Business School (BI), Nydalveien, Olso, Norway \\ Email: a.furnham@ucl.ac.uk
}

Received 14 December 2015; accepted 11 February 2016; published 14 February 2016

Copyright (C) 2016 by author and Scientific Research Publishing Inc.

This work is licensed under the Creative Commons Attribution International License (CC BY).

http://creativecommons.org/licenses/by/4.0/

(c) (i) Open Access

\begin{abstract}
The objective of this study was to investigate the relationship between IQ, EQ and creativity. In all 158 British adults completed a cognitive ability, creativity and emotional intelligence test. Cognitive ability was positively but not significantly correlated with divergent thinking (creativity) but significantly negatively with both facet and domain emotional intelligence scores.
\end{abstract}

Keywords

Intelligence, Emotional Intelligence, Creativity

\section{Introduction}

There is an extensive rise in the literature on emotional intelligence (EI) which has two contrasting approaches: those that focus on ability and are derived from the original EI conceptualization (with a focus on being able to reason validly about emotions) and measures of self-report (trait) (which focus on the behavioural dispositions and self-perceptions of one's ability to recognize and understand emotions (Petrides \& Furnham, 2001, 2003).

Empirical work in this field would suggest that trait EI is more robustly related to, but distinct from, personality as measured by the Big Five (Petrides \& Furnham, 2001) and is quite different from ability EI (Petrides, Pérez-González, \& Furnham, 2007). Critics of ability measures of EI highlight the misconception that EI or competencies can be measured through self-report and the potential for faking on self-report EI measures. Similar criticisms of the measure were used in this study (Petrides et al., 2007). Other views position EI, and in particular trait EI, as an individual difference construct and therefore argue that EI exists within the same space as personality accounting for very little criterion variance above and beyond that of basic personality dimensions (Matthews, Zeidner, \& Roberts, 2002). Petrides et al. (2007) explore this in more detail and, in their study found evidence to suggest that EI is a distinct construct, partially because it is determined by a number of personality 
factors andit "exists at the lower levels of personality hierarchies" (p. 48) thus somewhat dispelling the myth that EI is simply personality "rebranded".

This study is on the relation between EI, IQ and creativity. There have been a number of studies on the relationship between EI and conventional cognitive ability/intelligence. Derksen, Kramer and Katzko (2002) found almost no relationship between the Bar-On EQi measure and General Mental Ability in a Dutch sample. Van der Zee, Schakeland and Thijs (2002) present a summary of early findings which point to a stronger relationship between EI and personality than the relationship between EI and general intelligence. In a study to determine the relationship between EI, cognitive ability, and personality with academic achievement, Newsome, Day and Catano (2000) found that many of the factors in the Bar-on measure of EI were closely related to traditional personality traits. Arteche, Chamorro-Premusic, Furnham and Crump (2008) found very little relationship between the Bar-On measure and the Watson-Glaser Critical Thinking test. Di Fabio and Saklofske (2014) used three EI tests and the Ravens Progessive Matrices in Italian students and found on the MSCEIT ability level of IQ related to intelligence ( $r=0.31, N=194$. More recently in a brain mapping study, Barbey, Colom and Grafman (2014) found a significant relationship between EI and various measures of intelligence.

There seems however to be far fewer studies on EI and creativity. Zhou and George (2003) argued that the EI of a leader can and does have an impact on the creativity of their followers. In an empirical study done in Spain, Sanchez-Ruiz, Hernandez-Torrano, Perez-Gonzalez, Batey and Petrides (2011) found EI to be linked to divergent thinking and a measure of the "creative personality". Carmeli, McKay and Kaufman (2013) argued that EI is linked to creativity but that it is mediated through other factors like trait generosity and vigor.

This study looked at the relationship between a multidimensional measure of EI and both robust measure of intelligence as well as a divergent thinking task. Based on the above literature it was expected that there would be significant positive correlations between all the variables.

\section{Method}

\subsection{Participants}

There were 158 British adults (116 males) attending an assessment centre. They ranged in age from 32 to 49 years $(M=36.3$ yr., $S D=5.8)$. All were fluent in English.

\subsection{Measure and Procedure}

Bar-On Emotional Quotient Inventory (Bar-On, 2004). The Emotional Quotient Inventory (EQ-i), EQ-360 \& EQ-I: YV were developed to assess the Bar-On model of emotional-social intelligence. The EQ-I is a self-report measure designed to measure a number of constructs related to EI. The EQ-i consists of 133 items and takes approximately 30 minutes to complete. It gives an overall EQ score as well as scores for the five composite scales and 15 subscales (Bar-On, 2004, 2006). The manual reports acceptable levels of reliability of the test.

Graduate and Managerial Assessment; Abstract (GMA: A; Blinkhorn, 1985) This is a timed (30 min) high level test of abstract reasoning ability, which measures the ability to think conceptually, to discover underlying patterns within a set of information, and to switch easily between contexts and level of analysis. The test is made up of 115 questions split into 23 groups of five questions. There are two different scoring methods, the Lenient score (GMA-L), which measures the total number of individual questions that are correct, and the Harsh score (GMA-H), in which a mark is assigned for each group of five questions that are answered correctly.

Consequences (Christensen et al., 1953). This study used the Consequences Test (Christensen, Merrifield, \& Guilford, 1953, 1958). It contains a number of questions like "what would be the consequences if everyone suddenly lost the ability of read and write?" or "what would be the consequences if none of us needed food any more to live?" Participants are given a specific time either per problem or for all problems. Responses as for other DT tests may be assessed quantitatively or qualitatively. This is usually done by consensual rating techniques where a pool of expert and/or trained judges make a range of specific judgments with respect to issues like overall quality, originality and realism as well as complexity, use of principles or the number of positive vs. negative outcome. Perhaps the best-known scoring technique is that of Hennessey and Amabile (1988) with specified six principles, while others (i.e., Mumford, Marks, Connelly, Zaccaro, \& Johnson, 1998) have added others. The following is a good example The Consequences Test has been tested with regard to its divergent and convergent validity as well as its concurrent and predictive validity (Gelade, 1995; Vincent, Decker, \& Mum- 
ford, 2002). The test has been used in various vocational settings to look at such issues as leadership skills and performance (Connelly, Gilbert, Zaccaro, Threlfall, Marks, \& Mumford, 2000). In this study it is used as the criterion measure of creativity.

\section{Results and Discussion}

\section{Statistical Analysis}

Two types of analyses were done: first correlations between all variables (Table 1), second regressions with intelligence and creativity as the criterion score.

Participants' estimates of their IQ varied between 16 and 46 with a mean of $27.9(S D=4.8)$. According to the manual, this would put them on the 82nd percentile. This would "translate" to 115 on a standard IQ test. There was, however, a sex difference in scores: the mean for men was $29.1\left(S D=5.0,88^{\text {th }}\right.$ percentile $)$ and for women was $26.5\left(S D=4.3,78^{\text {th }}\right.$ percentile). This difference was statistically significant $\left(F=11.59, p<0.001 ; \eta^{2}=\right.$ 0.27). However, their actual scores were high.

The correlation results showed three things: First, cognitive ability (intelligence) was positively but not significantly correlated with creativity $(r=0.12)$ but significantly negatively correlated with all five EQ subscales as well as the total EQ score $(r=-0.19)$. The correlation between creativity and total EQ was not significant $(r=$ $0.08)$. The correlations between the five emotional facet scale scores were Intrapersonal $(r=-0.13)$, Interpersonal $(r=-0.22) \mathrm{SM}(r=-0.14)$ Adaptability $(r=-0.12)$ and General Mood $(r=-0.17)$.

Thereafter, two multiple regressions were computed, the first with intelligence (GMA) and the second with creativity (Divergent Thinking) as the criterion variable. The predictor variables were gender and the five EI facets. Neither regression was significant.

Previous results in the area of EI, cognitive ability and creativity are equivocal mainly because of the very different instruments used to measure these three factors. Whilst it is probably the case that all measures of cognitive ability are relatively highly inter-correlated indicating the existence of " $g$ " (general intelligence), this is not the case with either EI or creativity (Furnham, 2008).

There were two interesting findings from this study. The first was the EI was negatively correlated with IQ: that is the people of higher IQ had lower EI. There are various possible explanations for this. The first is that people with a higher IQ need not develop strong EI as they are able to solve many problems without the assistance of others. Thus, Petrides, Frederickson and Furnham (2004) showed that EI moderated the relationship between cognitive ability and academic performance. That is, less intelligent pupils with a higher EI did better at school because they were able to access help and support more easily.

The second explanation may be more concerned with response style. It is possible that less intelligence people overestimate the EI score. Equally it is possible that the data collection setting for this study (an assessment centre) encouraged people to do some impression management with their self-reported EI score. Self-report, but not ability measures, are open to social desirability responding. Certainly this finding merits further investigation.

Table 1. Correlations and descriptive statistics.

\begin{tabular}{|c|c|c|c|c|c|c|c|c|c|c|}
\hline & Mean & SD & Creativity & Intra EQ & Inter EQ & SM EQ & Adapt EQ & GM EQ & Total EQ & Gender \\
\hline Intelligence & 8.13 & 3.19 & 0.12 & -0.13 & -0.22 & -0.14 & -0.12 & -0.17 & -0.19 & 0.09 \\
\hline Creativity & 38.82 & 11.45 & & 0.15 & 0.08 & 0.03 & -0.01 & 0.15 & 0.08 & 0.09 \\
\hline Intrapersonal EQ & 104.53 & 13.74 & & & 0.64 & 0.64 & 0.68 & 0.80 & 0.88 & -0.26 \\
\hline Interpersonal EQ & 96.26 & 12.39 & & & & 0.56 & 0.62 & 0.65 & 0.79 & 0.05 \\
\hline Stress management EQ & 104.25 & 13.13 & & & & & 0.82 & 0.72 & 0.85 & -0.29 \\
\hline Adaptabilty EQ & 105.21 & 12.07 & & & & & & 0.71 & 0.89 & -0.24 \\
\hline General Mood EQ & 104.16 & 12.51 & & & & & & & 0.88 & -0.24 \\
\hline Total EQ & 103.31 & 11.59 & & & & & & & & -0.26 \\
\hline Gender & 1.25 & 0.44 & & & & & & & & \\
\hline
\end{tabular}

Gender was coded 1 = Female; 2 = Male. 
In this study EI was not related to creativity as measured by a divergent thinking test. This may be due to the unreliability of both instruments. Equally it could be that these results reflect reality in the sense that these two concepts are not related, but if they are various mediator or moderator variables not measured in this study account for the results.

Like all others this study had limitations. The participant group was relatively small and not representative of the population as a whole. As there are many tests of the three major variables (IQ, EQ, Creativity) used in this study it would be very desirable to replicate these findings using different measures and different populations. Future work in this area would benefit from developing and then testing a theory that explains the relationship between these three variables.

\section{References}

Arteche, A., Chamorro-Premuzic, T., Furnham, A., \& Crump, J. (2008). The Relationship of Trait EI with Personality, IQ and Sex in a UK Sample of Employees. International Journal of Selection and Assessment, 16, 421-426. http://dx.doi.org/10.1111/j.1468-2389.2008.00446.x

Barbey, A., Colom, R., \& Grafman, J. (2014). Distributed Neural System for Emotional Intelligence Revealed by Lesion Mapping. SCAN, 9, 265-272.

Bar-On, R. (2004). The Bar-On Emotional Quotient Inventory (EQ-i): Rationale, Description and Psychometric Properties. In G. Geher (Ed.), Measuring Emotional Intelligence: Common ground and controversy. Hauppauge, NY: Nova Science.

Bar-On, R. (2006). The Bar-On Model of Emotional-Social Intelligence (ESI). Psicothema, 18, 13-25

Blinkhorn, S. (1985) Graduate and Managerial Assessment Manual and User Guide. Dorchester: Dorset.

Carmeli, A., McKay, A., \& Kaufman, J. (2013). Emotional Intelligence and Creativity. Journal of Creative Behavior, 48, 290-309. http://dx.doi.org/10.1002/jocb.53

Christensen, P. R., Merrifield, P. R., \& Guilford, J. P. (1953). Consequences form A-1. Beverly Hills, CA: Sheridan Supply.

Christensen, P. R., Merrifield, P. R., \& Guilford, J. P. (1958). Consequences: Manual for Administration, Scoring, and Interpretation. Beverly Hills, CA: Sheridan Supply.

Connelly, M. S., Gilbert, J. A., Zaccaro, S. J., Threlfall, K. V., Marks, M. A., \& Mumford, M. D. (2000). Exploring the Relationship of Leadership Skills and Knowledge to Leader Performance. The Leadership Quarterly, 11, 65-86. http://dx.doi.org/10.1016/S1048-9843(99)00043-0

Derksen, J, Kramer, I., \& Katzko, M. (2002). Does a Self-Report Measure for Emotional Intelligence Assess Something Different than General Intelligence? Personality and Individual Differences, 32, 37-48. http://dx.doi.org/10.1016/S0191-8869(01)00004-6

Di Fabio, A., \& Saklofske, D. (2014). Comparing Ability and Self-Report Trait Emotional Intelligence, Fluid Intelligence, and Personality Traits in Career Decision. Personality and Individual Differences, 64, 174-178. http://dx.doi.org/10.1016/j.paid.2014.02.024

Furnham, A. (2008). Personality and Intelligence at Work. London: Routledge. http://dx.doi.org/10.4324/9780203938911

Gelade, G. (1995). Creative Style and Divergent Production. Journal of Creative Behavior, 29, 36-53. http://dx.doi.org/10.1002/j.2162-6057.1995.tb01422.x

Hennessey, B. A., \& Amabile, T. M. (1988). The Conditions of Creativity. In R. J. Sternberg (Ed.), The Nature of Creativity: Contemporary Psychological Perspectives (pp. 11-38). Cambridge: Cambridge University Press.

Matthews, G., Zeidner, M., \& Roberts, R. D. (2002). Emotional Intelligence: Science and Myth. Cambridge, MA: MIT Press.

Mumford, M. D., Marks, M. A., Connelly, M. S., Zaccaro, S. J., \& Johnson, J. F. (1998). Domain-Based Scoring in Divergent-Thinking Tests: Validation Evidence in an Occupational Sample. Creativity Research Journal, 11, 151-163. http://dx.doi.org/10.1207/s15326934crj1102_5

Newsome, S., Day, A., \& Catano, V. (2000). Assessing the Predictive Validity of Emotional Intelligence. Personality and Individual Differences, 29, 1005-1016. http://dx.doi.org/10.1016/S0191-8869(99)00250-0

Petrides, K. V., \& Furnham, A. (2001). Trait Emotional Intelligence: Psychometric Investigation with Reference to Established Trait Taxonomies. European Journal of Personality, 15, 425-448. http://dx.doi.org/10.1002/per.416

Petrides, K. V., \& Furnham, A. (2003). Trait Emotional Intelligence: Behavioural Validation in Two Studies of Emotion Recognition and Reactivity to Mood Induction. European Journal of Personality, 17, 39-57. http://dx.doi.org/10.1002/per.466

Petrides, K. V., Frederickson, N., \& Furnham, A. (2004). The Role of Trait Emotional Intelligence in Academic Performance and Deviant Behavior at School. Personality and Individual Differences, 36, 277-293.

http://dx.doi.org/10.1016/S0191-8869(03)00084-9 
Petrides, K. V., Pérez-González, J. C., \& Furnham, A. (2007). On the Criterion and Incremental Validity of Trait Emotional Intelligence. Cognition and Emotion, 21, 26-55. http://dx.doi.org/10.1080/02699930601038912

Sanchez-Ruiz, M., Hernandez-Torrano, D., Perez-Gonzalez, J., Batey, M., \& Petrides, K. (2011). The Relationship between Trait Emotional Intelligence and Creativity across Subject Domains. Motivation and Emotion, 35, 461-473.

http://dx.doi.org/10.1007/s11031-011-9227-8

Van der Zee, K., Schakel, L., \& Thijs, M. (2002). The Relationship of Emotional Intelligence with Academic Intelligence and the Big Five. European Journal of Personality, 6, 103-125. http://dx.doi.org/10.1002/per.434

Vincent, A. S., Decker, B. P., \& Mumford, M. D. (2002). Divergent Thinking, Intelligence, and Expertise: A Test of Alternative Models. Creativity Research Journal, 14, 163-178. http://dx.doi.org/10.1207/S15326934CRJ1402_4

Zhou, J., \& George, J. (2003). Awakening Employee Creativity. Leadership Quarterly, 14, 545-568. http://dx.doi.org/10.1016/S1048-9843(03)00051-1 